\title{
MAPA DE CONFIABILIDADE: UM MÉTODO QUANTITATIVO PARA ANALISE DO GRAU DE CONFIANÇA NAS RECONSTRUÇÕES DIGITAIS DE PATRIMÔNIOS HISTÓRICOS DEMOLIDOS OU FORTEMENTE MODIFICADOS
}

\section{RELIABILITY MAP: A QUANTITATIVE METHOD FOR ANALYZING THE DEGREE OF RELIABILITY OF DIGITAL RECONSTRUCTIONS OF DEMOLISHED OR HEAVILY MODIFIED HISTORICAL HERITAGE SITES}

\author{
Emerson Bruno de Oliveira Gomes ${ }^{1}$, Talita Simão Luiz Araujo², Abner Simões Portilho \\ Ferraz ${ }^{3}$, Anna-Beatriz Bassalo Aflalo ${ }^{3}$.
}

\section{RESUMO:}

O presente trabalho propõe um "mapa de confiabilidade": método quantitativo que visa informar o grau de confiança da reconstrução virtual de um cenário do passado, cuja reconstituição tenha partido, principalmente, de fotografias e mapas de épocas anteriores. O método proposto é dividido em duas partes: a primeira se refere ao fluxo de produção do cenário 3D, que inclui a coleta de dados iconográficos e o cruzamento de mapas e fotos antigas, com vistas à modelagem tridimensional, e a segunda parte, que diz respeito à utilização de um algoritmo (produzido no software Rhinoceros ${ }^{\circledR}$ e plug-in Grasshopper ${ }^{\circledR}$ ) o qual através das informações das fotografias, realiza cálculos, cujo resultado é um mapa de calor que informa quais são as áreas que possuem maior ou menor grau de confiabilidade em relação às hipóteses do pesquisador sobre o aspecto arquitetônico e urbanístico do local reconstruído. Por fim, como forma de demonstrar a metodologia quantitativa, aplicou-se o algoritmo em duas reconstruções virtuais que retratam épocas diferentes de um mesmo lugar. Escolheu-se como estudo de caso o Largo de Nazaré, localizado na cidade de Belém. A comparação dos resultados entre ambas as épocas mostrou que, apesar de se tratar da mesma área e das mesmas técnicas de reconstituição virtual, os mapas ajudaram a esclarecer onde cada maquete digital necessitou de maior ou menor grau de dedução, portanto, mostrou-se útil para auxiliar os leitores sobre quais partes são mais ou menos confiáveis em relação aos registros do passado.

PALAVRAS-CHAVE: patrimônio histórico; iconografia; mapa de confiabilidade; reconstrução virtual.

\section{ABSTRACT:}

The present work proposes a "reliability map": a quantitative method that aims to inform the degree of reliability of the virtual reconstruction of a scenario of the past, whose reconstruction started mainly from photographs and maps from previous times. The proposed method is divided in two parts. The first refers to the production flow of the 3D scenario, which includes the collection of iconographic data and the crossing of old maps and photos, with a view to the three-dimensional modeling of the environment. The second concerns the use of an algorithm (produced in the software Rhinoceros ${ }^{\circledR}$ and plug-in Grasshopper ${ }^{\circledR}$ ), which, through the information in the photographs, performs the calculations whose result is a heat map that informs which are the areas that have greater or lower degree of reliability in relation to the researcher's archtectonic and urbanistic hypotheses about what the reconstructed site. Finally, as a way to demonstrate the quantitative methodology, the algorithm was applied in two virtual reconstructions that portray different moments of the same place. Largo de Nazaré, located in the city of Belém, was chosen as a case study. The comparison of the results between both periods showed that despite being the same area and the same virtual reconstitution techniques, the maps helped to clarify where each digital model required a greater or lesser degree of deduction, therefore, it proved to be useful to assist readers about which parts are more or less reliable in relation to the records of the past.

KEYWORDS: historical heritage; iconography; reliability map; virtual reconstruction.

How to cite this article:



${ }^{1}$ Universidade de Lisboa

2 Universidade Federal do Rio de Janeiro

${ }^{3}$ Universidade da Amazônia

Fonte de Financiamento: Não houve.

Conflito de Interesse: Declaramos não haver conflitos de interesse.

Ética em Pesquisa: Declaramos não haver necessidade.

Submetido em: 06/04/2021 Aceito em: 17/08/2021 


\section{INTRODUÇÃO}

A reconstituição virtual de lugares históricos já demolidos tem se mostrado uma prática crescente no campo do patrimônio cultural (GIOVANNINI, 2020), por exemplo nos trabalhos de Debevec, Yu, Borshukov (1998), Kozan e Kozan (2007), Boas (2015), Zuffo e Lopes (2008), Eliseo et al. (2009), Marques e Costa (2009), Gomes et al. (2018), D'agostino, Caldeiras, Borba (2020), e Melo (2020). Essas modelagens tridimensionais vêm se tornando relevantes no resgate e na apresentação de cenários arquitetônicos e urbanísticos do passado, proporcionando novas formas de explorar o lugar, além de torná-los mais acessíveis ao público, seja através de websites, aplicativos, jogos, ou outros meios (PARAIZO, 2016).

0 avanço dos recursos tecnológicos tem proporcionado constantes aprimoramentos nos processos de reconstrução digital, criando experiências que parecem cada vez mais precisas e realísticas aos olhos dos usuários. Entretanto, a sensação de realismo se dá, principalmente, por conta dos efeitos visuais e interativos que as tecnologias oferecem, mas, a depender do local, da época e dos dados coletados, a reconstrução terá trechos com maior ou menor fidelidade em relação ao que existia no passado. Esta diferença, por vezes, não fica clara para o leitor, o que pode ocasionar interpretações confusas ou, até mesmo, equivocadas por quem contempla o cenário reconstruído. Questões como essa são abordadas em documentos como a Carta de Londres e os Princípios de Sevilha, que enfatizam a necessidade de maior transparência e rigor científico nas reconstruções virtuais em pauta (BEACHAM; DENARD; NICCOLUCCI, 2006; DENARD, 2009; PUJOL-TOST et al., 2019).

Por se tratar de lugares que já não existem mais, ou foram fortemente modificados, técnicas que se popularizaram recentemente como o escaneamento a laser 3D ou drones por nuvens de pontos, possuem pouca ou nenhuma aplicabilidade devido ao hiato físico entre a época desejada e os dias atuais. Neste sentido, os pesquisadores frequentemente necessitam investigar registros documentais do passado para, posteriormente, realizar um cuidadoso cruzamento dos dados coletados no intuito de identificar, da forma mais confiável possível, as características físicas do local à época (BOAS, 2015). Neste sentido, é comum que tais documentos encontrados não sejam suficientes para uma reconstrução totalmente fidedigna do sítio, e, portanto, é compreensível que parte dessa modelagem virtual ocorra com base em deduções.

Especialmente em relação às áreas urbanas, é raro que o pesquisador obtenha documentos como plantas técnicas das edificações e, por vezes, as fotografias do passado, mapas e demais imagens históricas acabam por ser as únicas fontes da modelagem (GIOVANNINI, 2020). Mesmo nos raros casos em que é localizado um projeto completo e detalhado da época, o que já contribui bastante no processo, tal material técnico por si não representa garantia de que o lugar tenha sido efetivamente executado em conformidade e, neste sentido, as fotografias sobem a um patamar mais sólido enquanto evidências do passado (REILLY, 1991), pois, de modo geral, elas refletem um retrato do lugar no tempo e espaço, podendo expressar texturas, vegetações, pessoas, vestimentas, objetos, inclusive marcas do tempo como manchas, sujeiras, etc.

À vista disso, o problema tratado neste artigo ocorre quando o público-alvo, sejam pesquisadores, estudantes ou mesmo a população em geral, visualiza o resultado da reprodução 3D e, aos seus olhos, tal reconstrução acaba por transmitir uma mensagem homogênea de "fidelidade ao passado", parecendo possuir o mesmo nível de precisão nas suas diversas partes, quando, na verdade, certos trechos são fruto de hipóteses do autor, com maior ou menor probabilidade de acerto. 
A questão mencionada acima é acentuada caso alguns trechos com elevados níveis de dedução recebam tanta ou mais atenção do público do que outras partes mais confiáveis da modelagem, podendo gerar desde interpretações equivocadas até comentários e discussões que fujam ao que de fato foi reproduzido com maior confiabilidade.

Neste sentido, o presente trabalho tem como objetivo propor um "mapa de confiabilidade": um método quantitativo que visa informar o grau de confiança da reconstrução virtual de um cenário do passado, cuja reconstituição tenha partido principalmente de fotografias e mapas de épocas anteriores. Trata-se, portanto, de um fluxo de trabalho que inclui o uso de um algoritmo (produzido no software Rhinoceros $®$ e plug-in Grasshopper $®$ ), que, a partir das informações coletadas nas fotos, fará cálculos cujo resultado é um mapa de calor que indica quais são as áreas que possuem maior e menor grau de confiabilidade em relação às evidências fotográficas da época.

\section{ESTADO DA ARTE}

0 processo de representação de construções em 3D a partir de imagens 2D se tornou um assunto de interesse crescente na área de computação gráfica desde o final do século XX (MCMILLAN; BISHOP, 1995). A utilização de sistemas computacionais tridimensionais, quando aplicada a edificações do passado, possibilitam diversas formas de estudo, levando a um acúmulo, controle de dados e informações técnicas, especialmente as visuais, permitindo, entre outras coisas, que os usuários possam observar, navegar e, até mesmo, experimentar o local, por exemplo, com Realidade Virtual, oferecendo a percepção do espaço de modo aproximado ao que já foi um dia, bem como as transformações arquitetônicas e urbanísticas ocorridas com o passar dos anos (D'AGOSTINO; CALDEIRAS; BORBA, 2020).

Nesse sentido, várias pesquisas como a de Zuffo e Lopes (2008), Marques e Costa (2009), Canuto, Moura e Salgado (2016), Gomes et al. (2018) e D'agostino, Caldeiras, Borba (2020), retrataram o desenvolvimento de modelagens arquitetônicas construídas principalmente a partir da interpretação de imagens antigas, ou seja, locais que já foram demolidos ou muito modificados, e cuja visita in loco pouco contribui para a verificação de medidas ou formas geométricas, especialmente das fachadas dos prédios.

Assim, os trabalhos mencionados no parágrafo acima refletem modelagens baseadas principalmente na junção de informações advindas de iconografias e documentos técnicos, especialmente mapas cadastrais e fotos. 0 trabalho de Zuffo e Lopes (2008) é mais um exemplo, o qual trata da reconstrução do Largo da Sé, em São Paulo, aproximando-se do que havia no ano de 1911.

Outro exemplo foi produzido pelo Laboratório de Modelos Tridimensionais da Faculdade de Arquitetura e Urbanismo da Universidade de São Paulo - Labtri FAU USP, que de forma semelhante aos demais citados, resgatou virtualmente, por meio de modelagens digitais, o Largo São Francisco, um dos núcleos mais antigos da fundação da cidade de São Paulo (D'AGOSTINO; CALDEIRAS; BORBA, 2020). Neste caso os pesquisadores utilizaram recursos computacionais para realizar análise das edificações existentes em diferentes períodos, principalmente durante a segunda metade do século XIX, época escolhida para a reconstrução. Eles priorizaram a reconstituição de fachadas no mesmo ângulo de captura de fotos a fim de reverter a perspectiva linear em um plano bidimensional, ou seja, facilitando a identificação das medidas das elevações. Sua contribuição viabilizou a verificação e visualização de mudanças espaciais urbanísticas e arquitetônicas ocorridas com o passar dos anos no local de estudo (D'AGOSTINO; CALDEIRAS; BORBA, 2020). 
Além dos mencionados acima, o próprio município de Belém, cidade onde se localiza o estudo de caso deste artigo, possui espaços já descaracterizados ou demolidos, os quais foram recentemente reconstruídos em meio virtual, como o prédio da Fábrica Palmeira da década de 1950 (MELO, 2020); 0 Grande Hotel , década de 1940 (RAIOL, 2017); e o Boulevard Castilhos França do início do século XX (GOMES et al., 2018). Relevante mencionar ainda as investigações do Laboratório Virtual FAU/ITEC, que reproduziu em meio digital diversos equipamentos urbanos do passado, como os Clippers, edificações ao estilo arquitetônico Art Decó que serviam de abrigo para os ônibus Zeppelin (BASSALO, 2019b), além do antigo Reservatório Paes de Carvalho (BASSALO, 2019a).

Os trabalhos mencionados acima possuem em comum o uso de métodos científicos para identificar e reconstruir em meio digital espaços do passado. Com isso, o problema da transparência vem à tona, seja para documentar e disponibilizar o passo-a-passo deste processo (GIOVANNINI, 2020), seja para expor ao usuário a confiabilidade da reconstrução.

Nas referências analisadas, uma das formas de repassar clareza ao utilizador sobre quais edifícios se tinha mais ou menos informações construtivas foi observada no projeto SIMRio (BOAS, 2015). Na reconstrução, percebe-se uma gradação no nível de detalhamento, deixando alguns edifícios com superfície lisa. Isso contribui no sentido de deixar claro para o usuário que ali existia um prédio com tais proporções, porém seus detalhes construtivos não são conhecidos ou não foram encontrados dados suficientes para uma reconstrução confiável. Esta informação é repassada de maneira subliminar ao leitor.

\section{ESTUDO DE CASO}

Definiu-se como estudo de caso o Largo de Nazaré (atualmente chamado de CAN - Centro Arquitetônico de Nazaré), localizado na cidade de Belém-PA, no Brasil. Tal área é uma das mais relevantes no contexto histórico, cultural e econômico da cidade, tratando-se do lugar onde, há mais de 200 anos, são celebradas as festividades do Círio de Nazaré, uma das maiores e mais populares cerimônias religiosas do mundo, e considerada pelo IPHAN Patrimônio Cultural da Humanidade (IPHAN I - Círio de Nazaré, 2006, p. 11, 2006).

Os períodos escolhidos para investigação e análise foram 1900 a 1910 e 1950 a 1960 . 0 primeiro período foi marcado pelo chamado Ciclo da Borracha na Amazônia, quando ocorreu um "boom" financeiro na região e a cidade teve grandes transformações físicas e econômicas, alterando consideravelmente o panorama arquitetônico. Tal época foi chamada de "belle époque paraense" (SARGES, 2010).

No final da década de 1940, na chamada Era Vargas no Brasil, novos estilos arquitetônicos e investimentos financeiros imprimiram perceptíveis interferências no espaço urbano de Belém, cujo objetivo político era apresentar a cidade como "moderna" (VIDAL, 2016). Já o segundo período escolhido neste trabalho (1950 a 1960), caracterizou-se pela presença do movimento modernista na arquitetura da cidade, que modificou prédios, praças, meios de transporte urbano, entre outros. 

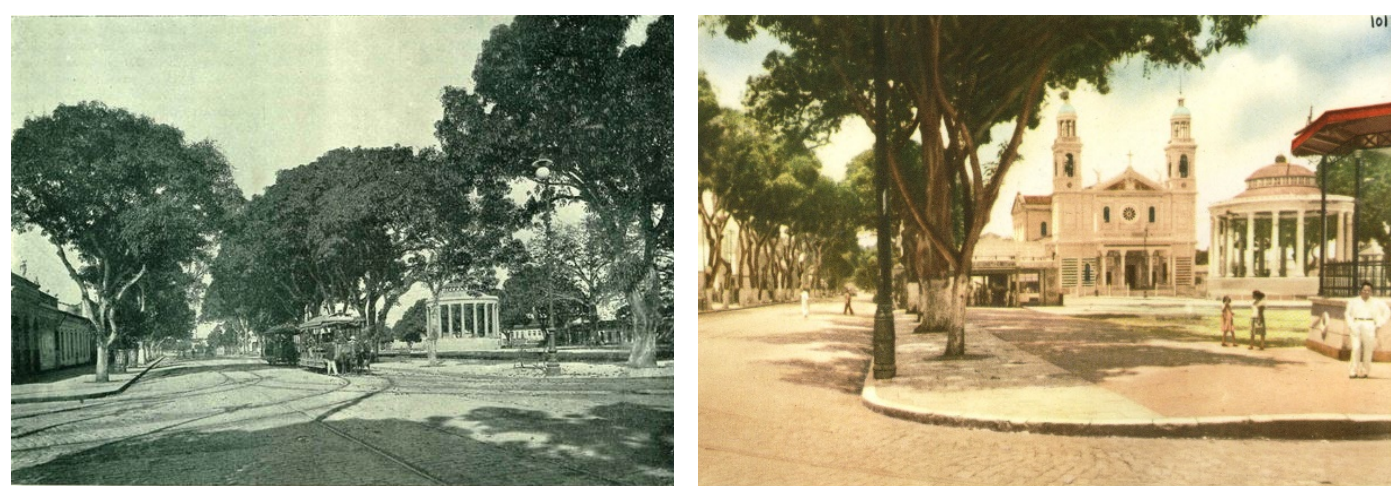

Figura 1. À esquerda. Cartão Postal do Largo de Nazaré no início do século XX.

Figura 2. À direita. Cartão Postal do Largo de Nazaré no meio do século XX.

Fonte: Álbum do Pará 1900 e Biblioteca online IBGE (disponível em https://biblioteca.ibge.gov.br/b ibliotecacatalogo.html?id=42480\&view =detalhes).

\section{METODOLOGIA}

0 processo metodológico aqui proposto se refere a um fluxo de trabalho que busca identificar de forma quantitativa o potencial de informações espaciais que um dado conjunto iconográfico pode fornecer para uma reconstrução digital histórica, especialmente no que diz respeito às fotografias do passado.

Com vistas a demonstrar a aplicabilidade do mapa de confiabilidade, optou-se por incluir na metodologia uma etapa de comparação de dois casos análogos. Escolheu-se, então, duas épocas distintas referentes ao mesmo lugar e se mantiveram os passos de reconstrução para ambas, inclusive reproduzindo imagens com o mesmo nível de acabamento fotorrealístico. Ao final, os resultados dos dois períodos foram confrontados, culminando em um fluxo dividido em 4 etapas:

1. Definição do local, períodos históricos e realização de pesquisa sobre informações técnicas e iconográficas;

2. Cruzamento de dados: cartografias urbanas (novas e antigas) e iconografias;

3. Identificação de dados técnicos das fotos: localização da origem, angulação, direção e outros.

4. Aplicação do algoritmo para quantificação e representação do mapa de confiabilidade.

\section{ETAPA 01 - DEFINIÇÕES SOBRE TEMPO/ ESPAÇO E PESQUISA BIBLIOGRÁFICA}

Nesta etapa, decidiu-se acerca do local e dos dois períodos distintos, quais sejam 1900 a 1910 e 1950 a 1960, em seguida se realizou uma minuciosa busca por informações históricas que pudessem auxiliar na caracterização física do lugar, em especial, fotos e mapas. Sites especializados, revistas e jornais da época, artigos científicos e livros, estão entre as principais fontes.

Os dados foram organizados em tabelas que simplificaram a filtragem das informações de cada fotografia como ano, fonte, local etc. No caso do Largo de Nazaré, cada época teve suas tabelas divididas em quatro partes, uma para cada vista da praça (quadrantes Norte, Sul, Leste e Oeste). Tal segregação facilitou a identificação e o sequenciamento das fachadas de acordo com a quadra correspondente. 
Tabela 1. Trecho da tabela referente ao período de 1910

Fonte: Os autores, 2021.



As tabelas foram alimentadas conforme as etapas posteriores se desenvolveram, acrescentando novas informações, como o ângulo de abertura das câmeras e a localização aproximada das mesmas no mapa (Tabela 1).

\section{ETAPA 02 - CARTOGRAFIAS E ICONOGRAFIAS}

Aqui os mapas antigos foram digitalizados em formato vetorial, através de ferramenta CAD e, após isso, sobrepostos a mapas mais recentes que possuem maior precisão (do século atual), de modo a obter uma cartografia da época passada, mas com maior precisão. Isso foi possível, porque o local escolhido não sofreu consideráveis alterações no desenho urbano, ou seja, algumas medidas como o comprimento de quadras, a largura de calçadas, e até mesmo determinados lotes, ainda estão preservados até hoje, servindo, portanto, de referência dimensional entre as épocas. Com isso, após o ajuste de escala, foi possível atribuir precisão mais confiável ao redesenho da planimetria do estudo de caso.

Ainda nesta etapa, realizou-se a verificação de proporcionalidade entre as divisas de lotes apontadas nos mapas originais e as dimensões das edificações nas fotos. Assim, foi possível confirmar a ordem sequencial das edificações, isso foi facilitado devido à organização por quadras nas tabelas.

0 resultado desta etapa foram dois mapas aproximados da área, um para cada época investigada. Os cruzamentos entre cartas e fotografias permitiu identificar elementos como calçadas, árvores, mobiliário urbano, entre outros.

\section{ETAPA 03 - DADOS TÉCNICOS DAS FOTOS}

Nesta etapa, de maneira aproximada, o pesquisador extraiu dados técnicos de cada fotografia como a localização do ponto de captura, a direção do alvo e o ângulo de abertura. 
Tais informações posteriormente serviram para alimentar o algoritmo com vistas a desenhar os cones das câmeras, ou seja, representar no mapa a planificação da área visível de cada foto.

No estudo de caso em questão, foi necessário demarcar os espaços não visíveis pelas câmeras, mesmo que estejam dentro do ângulo de visão. Tais áreas foram denominadas aqui de "geometrias de sombreamento" (Figura 3), referindo-se aos espaços que estão ocultos devido à existência de alguns elementos a sua frente (que podem ser edifícios, árvores de grande porte, entre outros). Trata-se de uma alteração no desenho do cone, para evitar que edificações "sombreadas" entrem na quantificação do algoritmo.
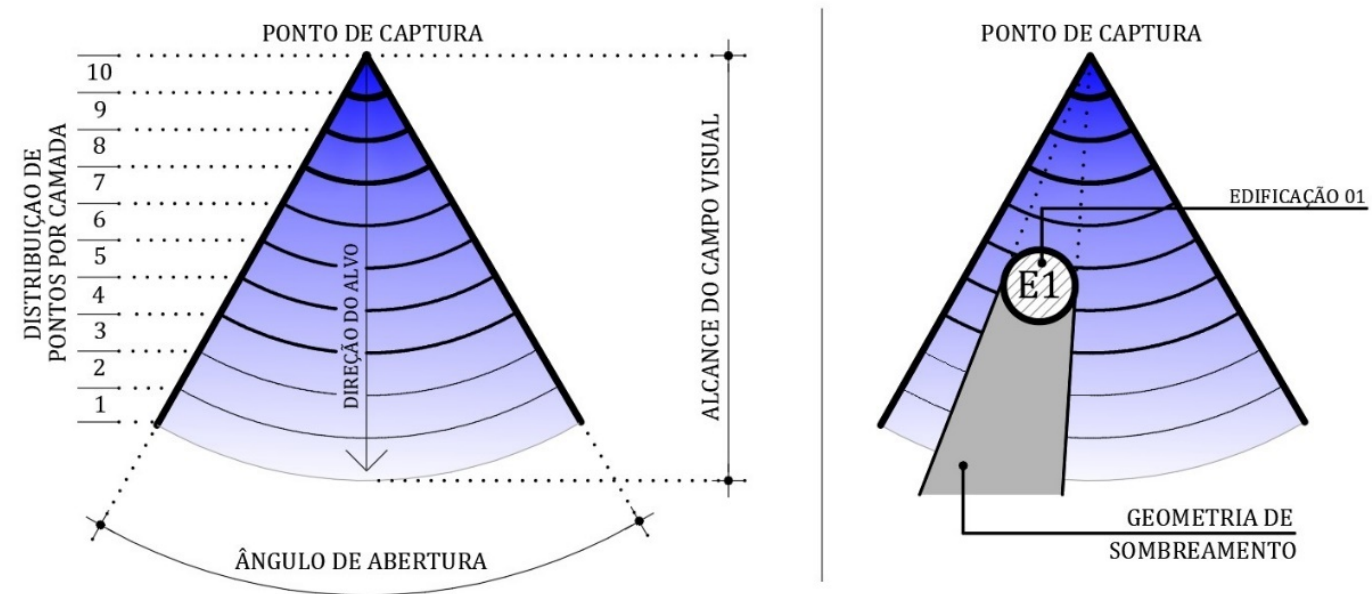

\section{ETAPA 04 - ALGORITMO}

Considerando o contexto de reproduções digitais de patrimônios históricos inexistentes, o desenvolvimento do algoritmo proposto partiu da premissa de que um elemento bem fotografado é aquele em que os diversos ângulos e detalhes puderam ser registrados com clareza através de diversas fotos, facilitando a percepção das informações físicas sobre o espaço. Em outras palavras, quanto mais áreas e elementos as fotografias puderem exibir sobre um dado objeto ou lugar, mais rico e mais preciso será o conjunto de informações e, por corolário, melhor tende a ser a fidelidade da reprodução.

0 foco durante a elaboração da programação foi a identificação do quanto o conjunto das imagens da época seria capaz de retratar com boa ou má qualidade os edifícios (apenas a casca externa). Para isso, considerou-se que, no contexto em questão, uma foto de boa qualidade permite observar com nitidez características como a geometria, as texturas, as marcas do tempo, entre outros. Assim, dadas as devidas limitações, o algoritmo criado se baseou na ideia de que, quanto mais próxima a câmera está do edifício, maior é a probabilidade de se observar tais características.

Para isso cada fotografia foi representada no mapa partindo do formato de um cone que, subdividido em várias camadas, distribui uma pontuação para cada prédio em razão da proximidade com o local de captura e da quantidade de possíveis obstáculos entre a origem do registro e o objeto registrado. Sempre que um edifício toca uma camada de maior valor, recebe tal pontuação. Edificações que aparecem em mais de uma foto têm seus pontos somados, de modo que quanto mais fotografadas elas forem, mais evidências se têm sobre aquela configuração física, logo, mais pontos vai receber.

Para exemplificar, a Figura 4 exibe a aplicação do algoritmo em uma circunstância genérica de uma vista superior (um mapa) com quatro edifícios: “A, B, C e D", capturados por duas câmeras: Cam1 e Cam2. Na situação 01 todas as câmeras estão desligadas, por isso os edifícios se
Figura 3. Esquema de distribuição de pontos por câmera.

No exemplo em questão, uma vista superior com quatro edificações (ou objetos) denominadas $\mathrm{A}, \mathrm{B}, \mathrm{C}$ e $\mathrm{D}$, e duas câmeras. 0 cálculo dos pontos e cores foi determinado pelo algoritmo

Fonte: Os autores, 2021. 
encontram com a tonalidade azul e todos os pontos ficam zerados. Na situação 02 apenas a Cam1 é ligada, com isso o prédio " $\mathrm{D}$ ” recebe a pontuação mais alta, por estar mais próximo da origem da foto. Já os edifícios "A" e "C" ficam zerados, "A" por estar fora do campo de visão gerado pela Cam1, e "C" por estar na área de sombreamento do prédio "D". A edificação "B" apesar de estar longe, é visível pela Cam1 e não existem obstáculos entre ela e "B", então recebe 3 pontos e fica em tom amarelado. Na situação 03 , ambas as câmeras são ligadas, logo, o prédio "A", mesmo estando alinhado a "B" e "C", recebe pontuação 5 em razão de sua distância para a Cam2 e de não estar localizado em nenhuma zona de sombreamento. "B" recebe 8 pontos, o mesmo que " $\mathrm{D}$ ", isso ocorre porque apesar de " $\mathrm{B}$ " estar mais distante que " $\mathrm{D}$ ", ambas as câmeras o capturam, portanto, as pontuações são somadas, pois ele aparece em duas fotografias diferentes, resultando na interpretação de maior quantidade de informações sobre o objeto em análise. Por fim, "C" permanece com pontuação zerada pois não é visto em nenhuma das duas fotos.

Figura 4. Esquema de distribuição de pontos por câmera.

No exemplo em questão, uma vista superior com quatro edificações (ou objetos) denominadas $A, B$,

C e D, e duas câmeras.

Fonte: Os autores, 2021.

Figura 5. Algoritmo desenvolvido no software Rhinoceros ${ }^{\circledR}$ e plug-in Grasshopper®. Seguindo 0 exemplo da imagem anterior, aqui são exibidos os códigos visuais para duas câmeras e quatro edifícios. Na primeira linha apresenta-se 0 algoritmo completo, dividido em três partes. Nas linhas seguintes mostram-se ampliadas cada parte.

Fonte: Os autores, 2021.

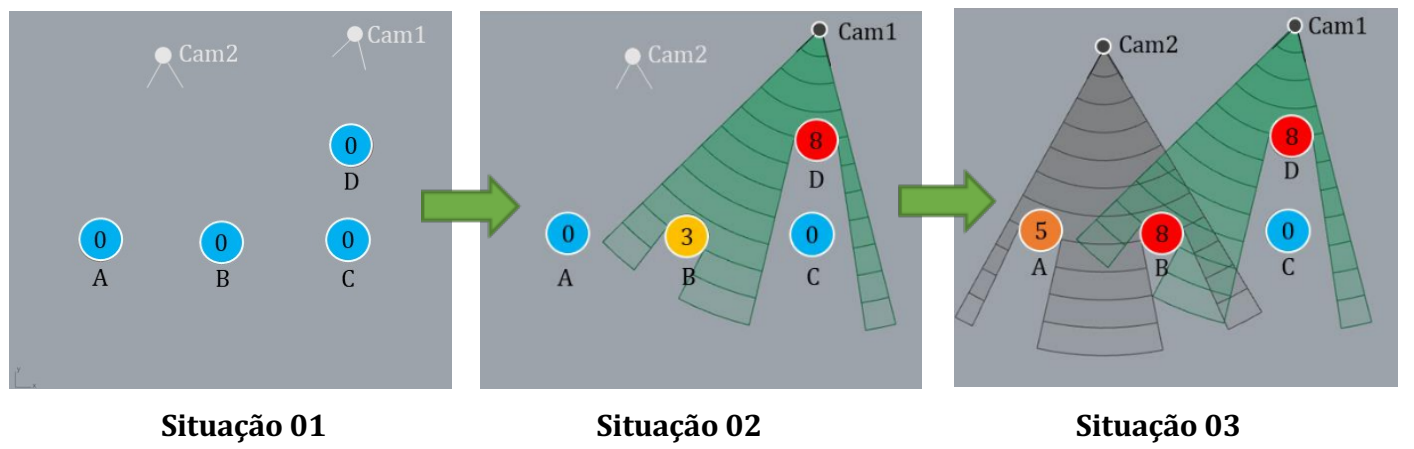

O código foi subdividido em três partes: a) As câmeras: elas necessitam ser alimentadas com dados como a localização do ponto de origem da foto, a direção do alvo, o ângulo de abertura, a resolução (quantidade de camadas) e a geometria de sombreamento; b) Os edifícios: eles precisam ser alimentados pela geometria dos prédios; e c) 0 processamento das cores: é a parte do código que calcula a somatória de pontos e atribui cores ao mapa. A Figura 5 apresenta o algoritmo.

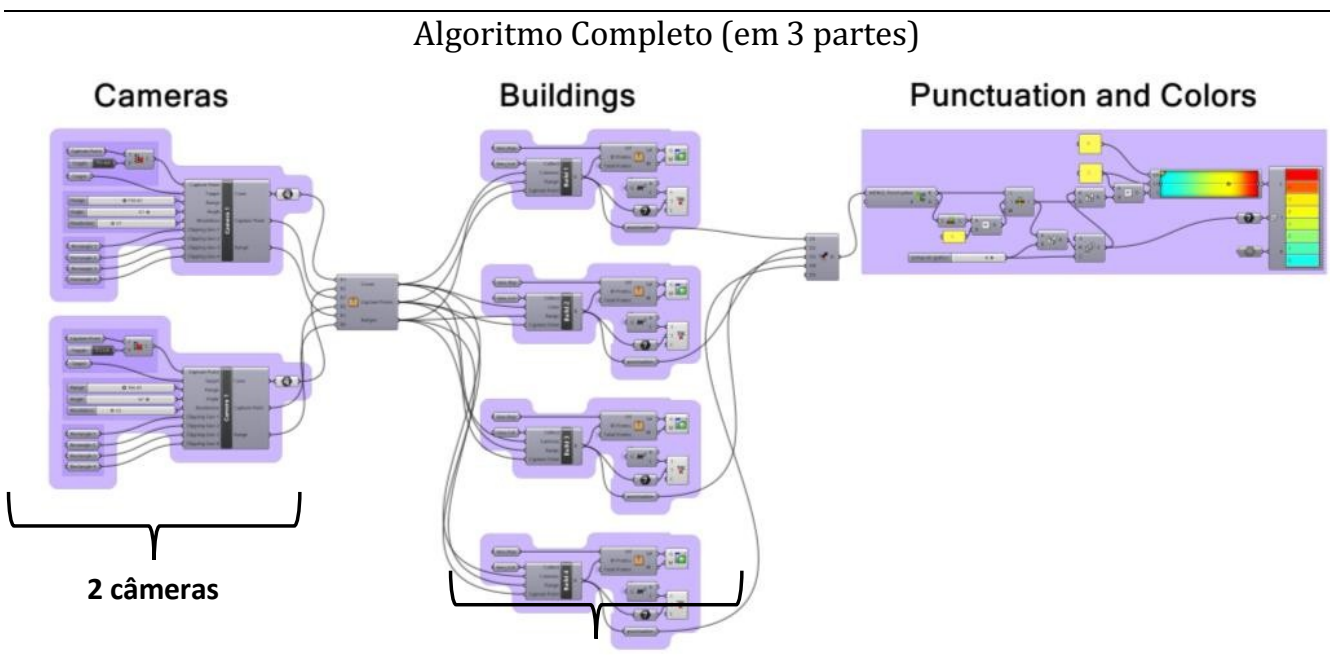

4 edifícios 


\section{Parte 1 - Câmeras}

Cada uma das fotografias analisadas pelo algoritmo deve ter para si uma cópia do conjunto de códigos da parte 1, apresentado na Figura 6. Para que funcione, é necessário inicialmente informar ao Grasshopper® quais são os pontos de captura (Capture point) e de alvo (Target). Em seguida é preciso indicar quais são as edificações que formarão algum tipo de "sombreamento", de modo a impedir a contagem de pontos em prédios que estejam atrás de outros.



No Grasshopper® a ferramenta Cluster se traduz numa forma de compactar um conjunto de códigos, transformando-os visualmente em uma única entidade, frequentemente facilitando a leitura e manipulação do algoritmo. Assim, na parte 1, uma destas compactações é a entidade denominada Camera 1, exibida na Figura 6 e expandida na Figura 7.

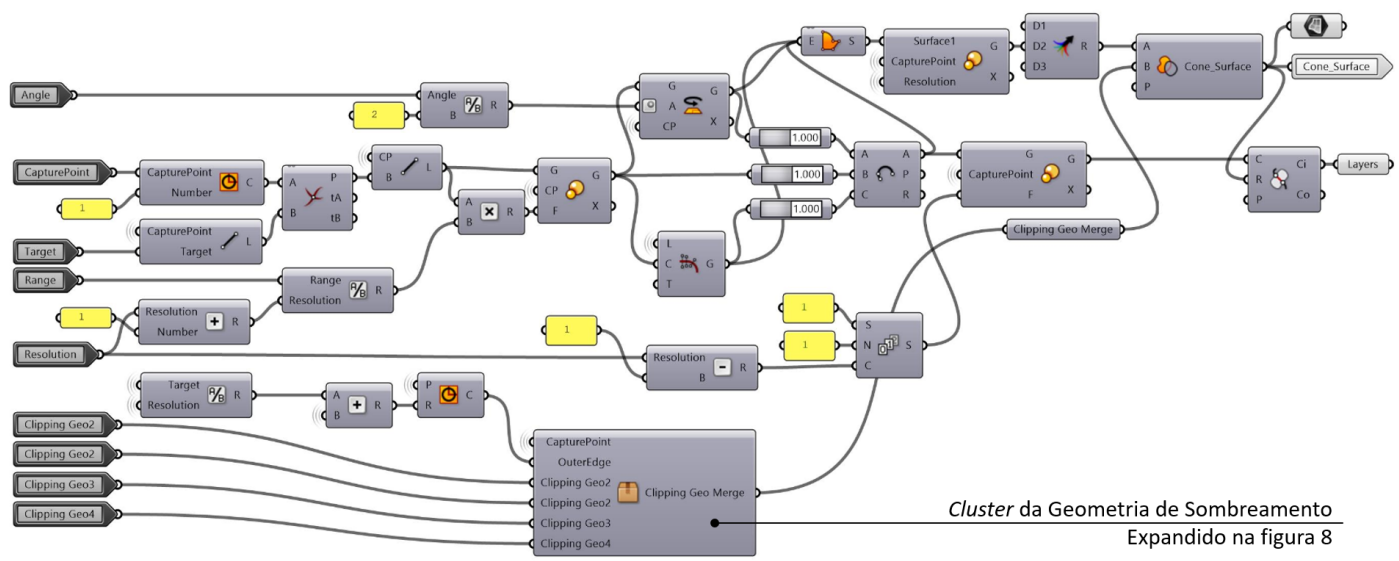

Após serem indicados no mapa os pontos de captura, alvo e as geometrias de "sombreamento", o código em pauta necessita que sejam ainda alimentadas as seguintes variáveis, relevantes para a configuração das câmeras:

\section{Distância (Range):}

Essa variável tem a função de determinar um limite de visibilidade para a câmera, que equivale à distância máxima do cone. Isso está diretamente vinculado à escala do mapa, e é necessária para limitar as áreas a serem calculadas pelo software. Por exemplo: em uma praça ou um
Figura 6. Detalhe da parte 1 do código, as câmeras.

Fonte: Os autores, 2021.

Figura 7. Expansão do Cluster de uma câmera.

Fonte: Os autores, 2021. 
bairro, é possível que tal variável atinja 100, 200, 500 ou mais metros, já no caso da análise do interior de uma edificação, provavelmente o valor será algo próximo de 10 ou 20 metros.

\section{Resolução (Resolution):}

A variável Resolução (Camadas) tem a função de indicar o número de segmentos do cone. Isso equivale à pontuação máxima que a câmera poderá aplicar em uma edificação. Então, quanto mais segmentos, maior a pontuação distribuída para os prédios mais próximos.

Assim, por exemplo, se o número de camadas estiver configurado para 10, significa que um prédio que toque a primeira camada receberá 10 pontos, já um prédio que esteja na última camada receberá 1 ponto. Porém, se a resolução subir, por exemplo, para 30, então o prédio da primeira camada recebe 30 pontos enquanto o da última permanece recebendo apenas 1 ponto.

Esta variável permite, então, aumentar a diferença entre a pontuação de prédios mais próximos e mais distantes e com isso minimizar possíveis distorções na distribuição dos pontos. Ou seja, no caso de a resolução estar definida em 10, será necessário que um prédio distante (na última camada) seja exibido em pelo menos 10 fotos para que a sua pontuação possa equivaler à de um edifício que esteja na primeira camada de uma câmera (recebendo igualmente 10 pontos). Por outro lado, se o algoritmo estiver ajustado, por exemplo, para 50 camadas, será necessário que este mesmo edifício posicionado na última camada seja exibido em 50 ou mais fotos para que ocorra tal equivalência.

\section{Ângulo (Angle):}

Tem a função de indicar a abertura da câmera. Este valor vem pré-configurado em 60 graus, mas deve ser ajustado foto a foto, cabendo ao utilizador identificar, a partir dos objetos visíveis nas bordas das imagens, a angulação aproximada de cada fotografia.

\section{Geometria de sombreamento (Clipping Geo):}

Trata-se da necessidade de informar, em cada câmera, quais são as barreiras visuais que devem impedir que as camadas de pontuação avancem para as áreas atrás dos prédios. Uma vez indicada a barreira visual (um polígono que demarque um prédio ou um conjunto de prédios), o algoritmo calcula automaticamente a projeção da área de sombreamento. Na Figura 8 o código da Geometria de Sombreamento (Clipping Geo) é expandido, demonstrando o cone da câmera, a edificação e a área a ser recortada. Tal área de sombreamento fica invisível na imagem final do mapa.

Figura 8. Detalhe do Cluster da Geometria de Sombreamento (Clipping Geo). A linha tracejada indica a entidade do Grasshopper $\circledast$ correspondente à figura geométrica do mapa.

Fonte: Os autores, 2021.






\section{Parte 2 - Edificações}

Cada edificação ou cada fachada deve corresponder a um conjunto de códigos da parte 2 , conforme a Figura 9. Assim, para o correto funcionamento é necessário realizar a duplicação de tal conjunto até atingir o número de edificações, e, em seguida, é preciso vincular cada prédio a duas entidades específicas, que foram chamadas aqui de Geometria de Representação (Geo_Rep) e Geometria de Coleta (Geo_Col), conforme Figura 9.

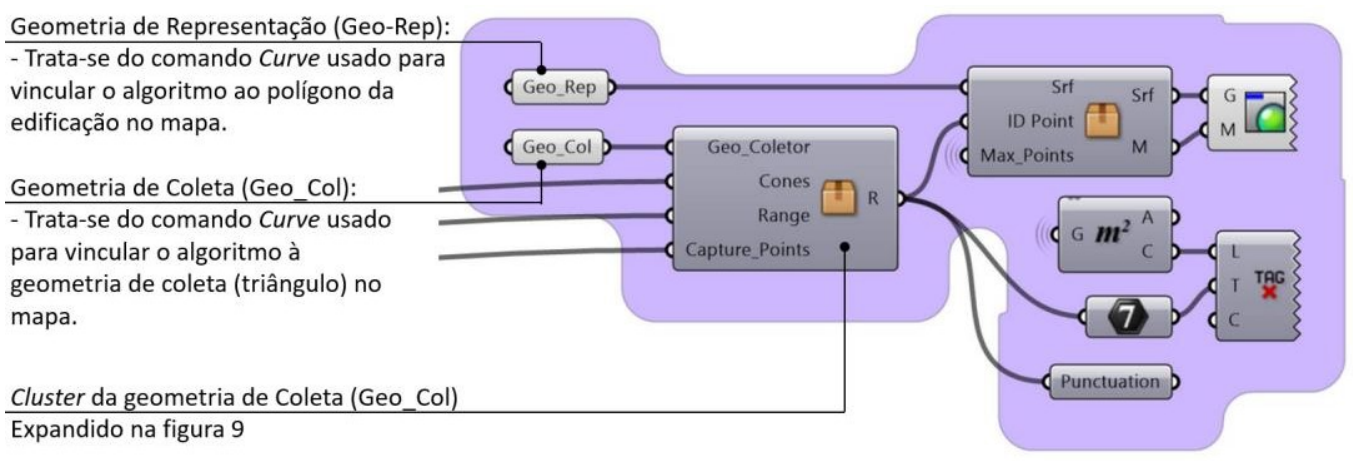

A Geometria de Representação (Geo_Rep) deve estar vinculada ao polígono da edificação em si, ou seja, é onde o Grasshopper® vai representar a cor e a quantidade de pontos no mapa. Por vezes a Geo_Rep pode ser o mesmo polígono da Geometria de Sombreamento mencionada no tópico sobre câmeras, desde que se refira a uma única edificação.

Já a Geometria de Coleta (Geo_Col) é um polígono em formato triangular que deve ser desenhado junto à fachada de cada prédio. Ela é destinada tão somente a realizar a coleta de pontuação, devendo ser desligado quando da produção final do mapa. A coleta de pontuação ocorre através da geração de uma linha (oculta) que parte da coordenada do ponto de captura das fotos e atinge o centro da base do mencionado triângulo (Geo_Col). Esta é, portanto, a primeira função do triângulo: servir de alvo para os raios que partem das câmeras com o intuito de medir a distância.

A segunda função é validar, entre todas as câmeras, qual delas está efetivamente atingindo a fachada do prédio. Isso se dá pelo cruzamento, no mapa, entre o cone da câmera e a área do triângulo que foi posicionado junto à fachada. Assim, sempre que houver a interseção entre ambos (cone e triângulo), o valor da distância entre a câmera e o prédio é dado como positivo e, posteriormente, é convertido para a escala de camadas (Resolução) e finalmente exibido no centro da Geometria de Representação (Geo_Rep).

No gráfico da Figura 10, há uma única câmera (cam1) e 5 edifícios (A, B, C, D e E). Cada um destes prédios possui um pequeno triângulo desenhado à sua frente, que representam a Geometria de Coleta (Geo_Col). A partir da Cam1 seguem raios em direção a todos os prédios (Raios 1, 2, 3, 4 e 5), atingindo as fachadas das edificações, onde ficam localizadas as bases dos triângulos (Geo_Col). Tais raios ficam ocultos na versão final do mapa e são utilizados pelo algoritmo apenas para calcular do valor de distância entre a câmera e os prédios. Cada raio é sempre direcionado ao ponto médio da base do triângulo da Geo_Col. Ainda na Figura 10, na ampliação à direita, verifica-se que o Raio 5 , que partiu em direção ao prédio "E", não foi validado pela respectiva Geo_Col, pois não houve cruzamento entre a área do triângulo e o cone da câmera (cor rosa), logo, a pontuação de "E" ficou igual a zero, e a cor passou a ser fria.
Figura 9. Conjunto de comandos do Grasshopper $尺$ destinado a segregar as câmeras que visualizam as fachadas dos prédios e determinar a pontuação deles. Este conjunto precisa ser alimentado indicando no mapa quais são as geometrias Geo-Col e Geo_Rep.

Fonte:

Os autores, 2021. 
Figura 10. Esquema gráfico de demonstração do raio que

pare da câmera e atinge 0 eixo da fachada, usado para obter os valores de distância.

Na ampliação à direita, verifica-se que o Raio 5, que partiu em direção ao prédio "E”, não foi

validado pela respectiva

Geo_Col, pois não houve cruzamento entre a área do triângulo e o cone da câmera (cor rosa), logo, a pontuação de "E" ficou igual a zero, e a cor passou a ser fria.

Fonte:

Os autores, 2021.

Figura 11. Expansão do Cluster Geometria de Coleta. Destaque para o gráfico com a curva Bezier, destinado a redistribuir os pontos recebidos pelos prédios.

Fonte:

Os autores, 2021.

Figura 12. Demonstração da aplicação do gráfico de curva

Bezier para redistribuir os pontos em uma câmera. Na imagem da direita definiu-se uma linha reta, mantendo-se

os pontos igualmente distribuídos. Na imagem da esquerda a curva está suave para baixo, o que resulta em um aumento da pontuação dos prédios próximos e

consequentemente uma redução dos pontos conforme os prédios se distanciam.

Fonte:

Os autores, 2021.
Mapa de confiabilidade: um método quantitativo para análise do grau de confiança nas reconstruções digitais de patrimônios históricos demolidos ou fortemente modificados
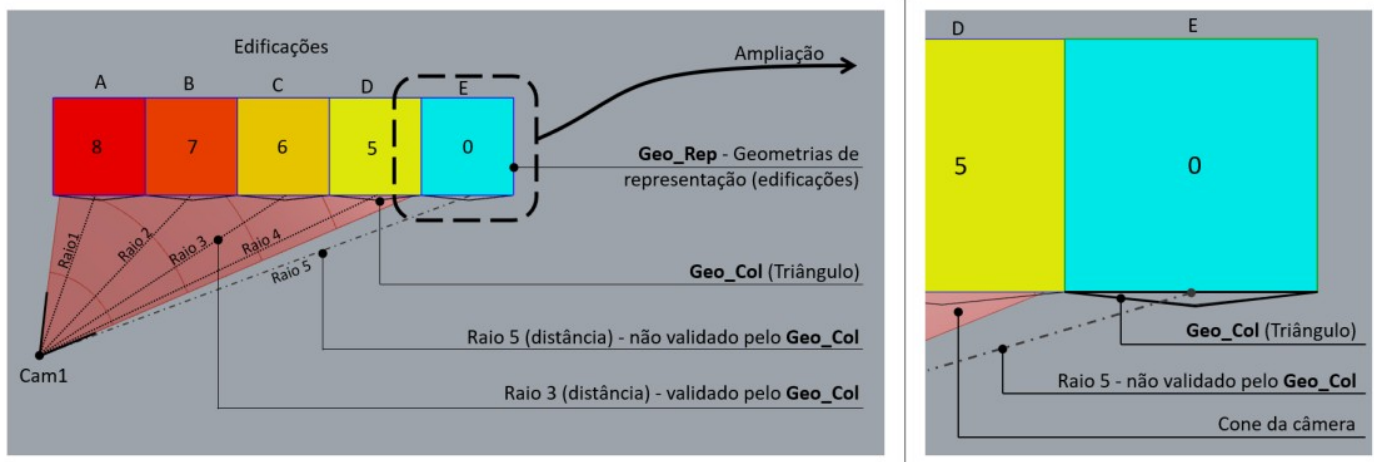

A Geometria de Coleta também foi configurada como um Cluster, conforme mencionado na Figura 9 e expandido na Figura 11. Neste sentido, com vistas a aumentar o controle por parte do utilizador, incluiu-se na Geo_Col um gráfico com uma curva Bezier, destinado a redistribuir os pontos recebidos pelos prédios. Esta opção foi criada para dar maior peso às imagens mais próximas que, de modo geral, apresentam melhor detalhamento e, portanto, devem receber valores mais elevados. A curva Bezier foi posicionada no código de modo que, ao ser modificada, todas as entidades receberão a mesma alteração, repetindo-se a distribuição entre todas as câmeras.

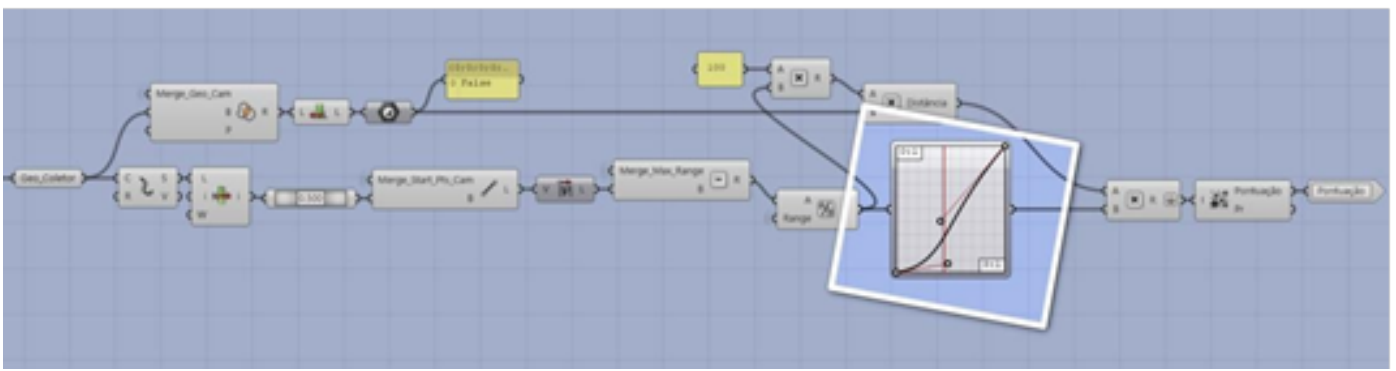

A curva Bezier em questão pode ser ajustada para ficar mais ou menos acentuada, conforme a necessidade do utilizador, podendo, inclusive, manter-se como uma linha reta, o que retornaria ao mapeamento original (distribuição uniforme dos pontos), conforme Figura 12.

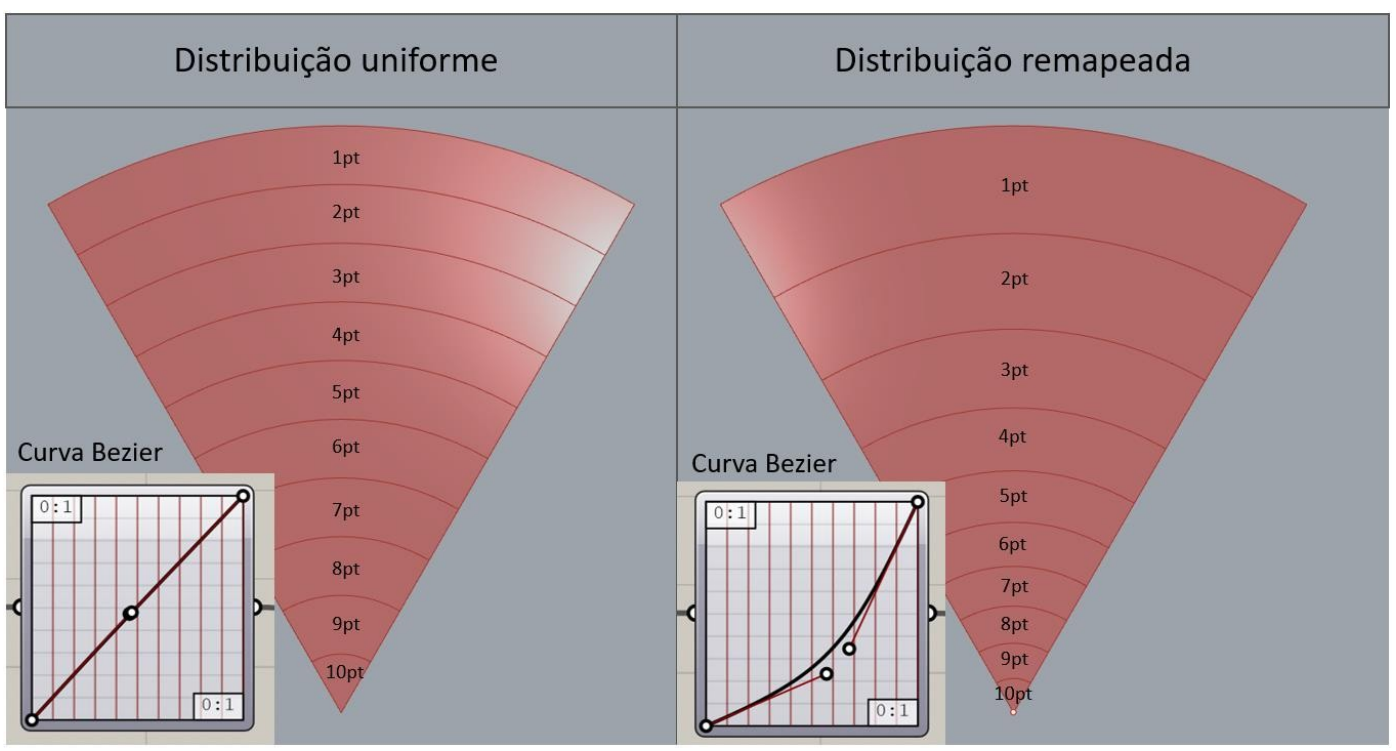




\section{Parte 3 - Pontuações e cores}

A parte final do algoritmo realiza a coleta dos pontos de todos os edifícios em uma lista única, que, ordenada de modo crescente, permite segregar o valor mais alto, o qual passa a figurar como o topo da escala de cores e será representado pela cor vermelha, demarcando a edificação que recebeu mais pontos. A base da escala será sempre igual a zero, representada pela cor azul, seguindo as tonalidades análogas a um mapa de calor.

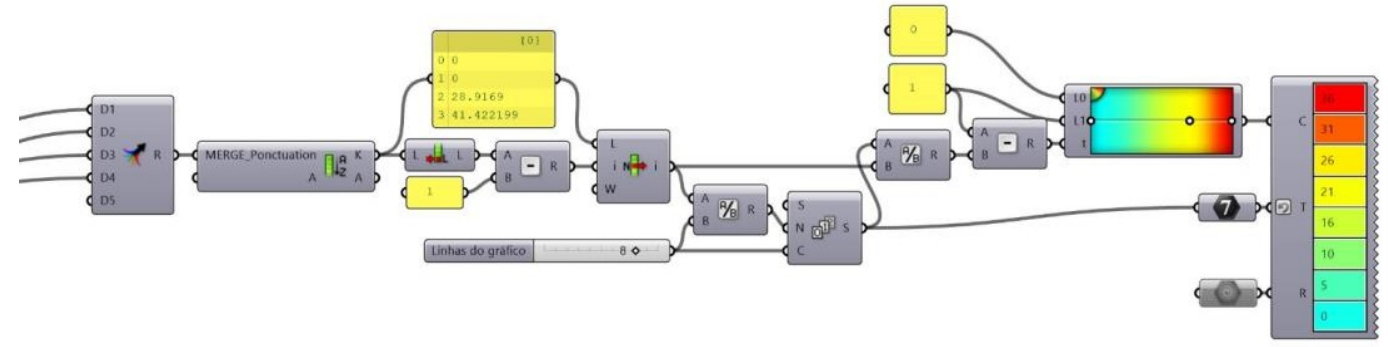

O algoritmo em pauta foi projetado para coletar dados relativos às fachadas das edificações, aplicando os resultados (número e cores) nas áreas de cada prédio (em planta), ou seja, quando o usuário observa o mapa, que é uma vista superior, a coloração de cada lote diz respeito à sua fachada visível.

Quando o edifício possui mais de uma fachada, como aqueles situados em uma esquina, optouse por subdividir sua planta em quantidades iguais ao número de fachadas, de modo a permitir que a leitura de cada face vertical do prédio (fachada) ocorresse dentro da área de seu lote.

Para exemplificar isso, a Figura 14 exibe um mapa contendo duas câmeras (Cam1 e Cam2) e 4 edificações (E1, E2, E3 e E4). No diagrama 1 (imagem da esquerda), mostra-se um mapa esquemático no qual os prédios E1 e E2 possuem apenas uma única fachada cada, representadas por "a" e "b", respectivamente. Já E3, por estar em uma esquina, possui duas faces para a rua, representadas por "c e d". E4, por sua vez, é visível de todos os lados, portanto suas faces são as letras "e, f, g, h, i e j". Assim, quando uma edificação possui mais de uma fachada visível, sua planta precisa ser dividida de modo que cada face tenha uma área correspondente destinada a receber coloração e pontuação. No Diagrama 02 (imagem da direita), o mapa esquemático, antes cinza, recebeu a aplicação do algoritmo, exibindo agora as cores e pontuações relativas à cada face visível

\section{DIAGRAMA 01}
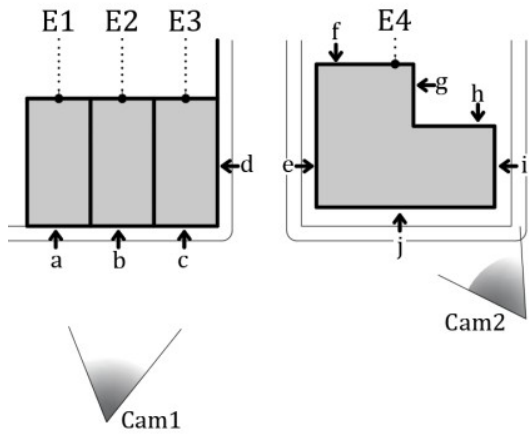

\section{DIAGRAMA 02}

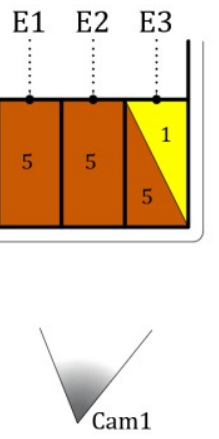

Figura 13. . Detalhe da terceira parte do algoritmo: pontuação e cores.

Fonte:

Os autores, 2021.
Figura 14. Exemplo de subdivisão das plantas dos edifícios em quantidades iguais ao número de fachadas, de modo que cada plano vertical externo tenha uma área disponível para receber cor e pontuações específicos.

No Momento 01, as letras minúsculas representam as fachadas de cada edificação No Momento 02 constam as divisões internas, as cores e as pontuações correspondentes.

Fonte:

Os autores, 2021. 


\section{RESULTADOS}

A primeira etapa metodológica, referente à pesquisa de informações técnicas e iconográficas, teve como resultado o total de 69 fotografias (36 da década de 1900 e 33 de 1950), além de cartografias e outros documentos que auxiliaram na reprodução do espaço. Posteriormente, com base no cruzamento das cartas e das imagens, produziram-se os mapas semicadastrais aproximados de cada época, cuja comparação entre ambos permitiu observar mudanças no desenho urbano, por exemplo a criação de uma vila chamada Leopoldina (na quadra Norte), a construção do Clipper (um ponto de ônibus com restaurante no andar superior) e a obra da atual Basílica de Nazaré que, durante a década de 50, dividia a quadra Leste com uma parte da antiga Igreja Matriz de Nossa Senhora de Nazaré do Desterro, hoje demolida. As demais intervenções, e mais evidentes pelas fotografias, em sua maioria, são referentes a reestruturação arquitetônica de residências e comércios, principalmente no que diz respeito ao estilo arquitetônico, pois, durante estes 60 anos, a cidade sofreu forte influência do movimento moderno.

Os mapas semicadastrais também permitem observar que foram poucas as mudanças em relação à união ou desmembramento de lotes, bem como às larguras das calçadas, arborização, entre outros. Cada mapa apresenta o traçado de vias, passeios públicos, lotes, equipamentos, mobiliários urbanos, arborização e outros, conforme Figura 15.

Figura 15. Mapas com traçado urbanos aproximados referentes aos dois períodos em estudo.

Fonte:

Os autores, 2021.

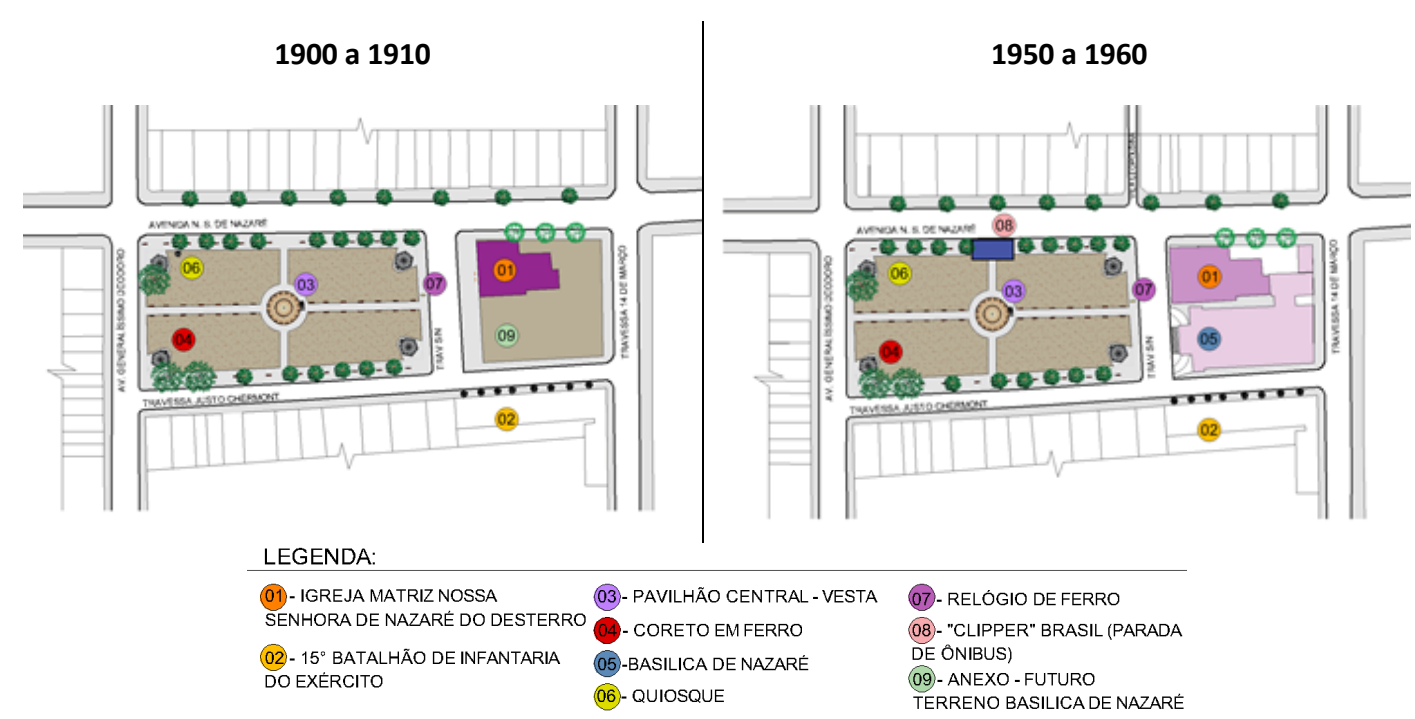

Posteriormente, em cada mapa, posicionaram-se os cones das câmeras, informando para o algoritmo dados aproximados sobre os pontos de origem, a direção, o ângulo etc. 0 produto disto foi um conjunto de sobreposições de cones. Com isso, após conectar todas as geometrias das cartografias ao código visual, obteve-se como resultado os mapas cuja legibilidade é indicada por um termômetro de calor informando as áreas em que os pesquisadores tiveram mais evidências fotográficas para reconstruir o modelo virtual. Utilizou-se os tons quentes como o vermelho e amarelo, para representar níveis mais elevados e tons frios, como o verde e azul, para níveis menores, conforme Figura 16. 


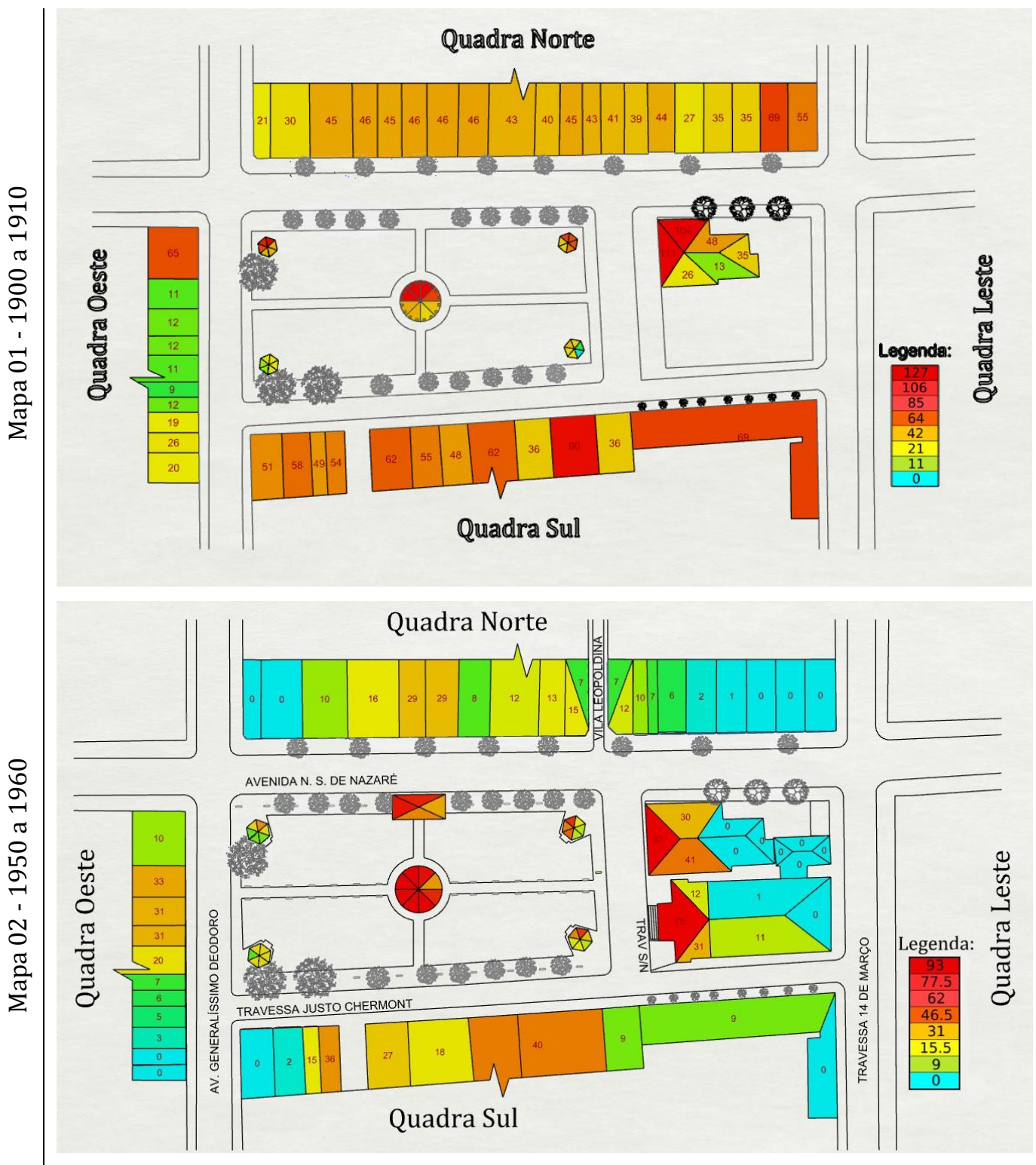

Figura 16. Mapas de confiabilidade referentes aos dois períodos em estudo.

Fonte:

Os autores, 2021.

No mapa 01 (1900-1910) nenhuma das edificações ficou com baixa pontuação, predominando a cor laranja e vermelho, ou seja, a maioria dos prédios foram consideravelmente exibidos nas fotos, o que representa algo positivo para a reconstrução, pois de modo geral as deduções tiveram um ponto de partida mais confiável. Já no mapa 02 (1950-1960), a coloração azul e verde é marcante, informando que as evidências fotográficas foram menos esclarecedoras em certos lugares, portanto, há mais áreas com pouca comprovação.

Na Tabela 2 abaixo, constata-se que para 1900-1910, 56\%\% das áreas apresentaram tonalidades com pontuações entre 33 e 64 (amarelado), $16 \%$ mantiveram suas tonalidades acima de 65 e $27 \%$ ficaram abaixo de 32, apresentando tons mais frios. Já no mapa de 19501960, 70\% das áreas apresentaram tonalidades abaixo de 23 pontos, em tons mais frios, $19 \%$ mantiveram suas tonalidades entre 25 e 46 (amarelado), e 10\% ficaram acima de 47 , com tons mais quentes.

Como forma de simplificar a comparação entre os mapas, dividiu-se o local em seis partes iguais: quadras Norte, Sul, Leste, Oeste, Coretos e Pavilhão. Com isso, segregaram-se as quantidades e cores em quatro intervalos, conforme a Tabela 1: azul (0 a 25\%), amarelo (26 a 
Tabela 2. Porcentual elaborado a partir dos pontos finais gerados pelo algoritmo no mapa de confiabilidade

Fonte: Os autores, 2021.

Figura 17. Imagens das reconstruções tridimensionais dos anos de 1900-1910 (à direita) e 1950-1960 (à esquerda).

Fonte:

Os autores, 2021.

Mapa de confiabilidade: um método quantitativo para análise do grau de confiança nas reconstruções digitais de patrimônios históricos demolidos ou fortemente modificados

50\%), laranja (51 a 75\%) e vermelho (76 a 100\%), tornando possível a classificação das partes por intervalo, conforme a tabela abaixo.

\begin{tabular}{c|c|c|c|c}
\hline & Azul & Amarelo & Laranja & Vermelho \\
\hline 1910 & $27 \%$ & $56 \%$ & $10 \%$ & $6 \%$ \\
\hline 1950 & $70 \%$ & $19 \%$ & $4 \%$ & $6 \%$ \\
\hline
\end{tabular}

Em ambos os mapas da Figura 8, os objetos centrais do Largo como a Igreja Matriz de Nossa Senhora do Desterro (1910) a Basílica de Nazaré (1950), o Pavilhão Central e o Clipper (1950) possuem tonalidades mais próximas à cor vermelha, sendo, portanto, as edificações de maior pontuação, ou seja, são mais bem explicadas pelas câmeras, logo podem ser reconstruídos com maior confiabilidade. Já as construções residenciais ou comerciais que circundam, acabam ficando em segundo plano na maioria das fotos, diminuindo a percepção dos detalhes construtivos, reduzindo então a confiabilidade em relação às principais evidências.

Ainda sobre os mapas da Figura 16, focando especificamente nas quadras Norte, Sul e Oeste, verifica-se que, no ano de 1910, o quarteirão sul foi o trecho no qual as suas construções foram mais pontuadas, enquanto em 1950 os pontos foram mais bem distribuídos entre os demais quarteirões. Isso é um indicativo de que, no início do século XX, a quadra Sul apresentava atrativo visual maior que as demais.

O comparativo entre os mapas indica ainda que cerca de 50\% dos dados coletados para 19001910 tiveram pontuação média, por outro lado, o de 1950-1960 obteve somente 20\% o tiveram. Além disso, em comparação com as pontuações mais próximas à cor vermelha (mais confiável), o mapa de 1900-1910 apresenta uma porcentagem maior em relação ao de 19501960, indicando uma quantidade maior de trechos fotografados. Isso sugere que, para a reconstrução tridimensional, o cenário do ano de 1910 possui um maior grau de fidelidade em relação ao de 1950, mesmo que o resultado da sua verificação tenha sido mediano.

Por fim, a imagem abaixo (Figura 17) demonstra a comparação dos cenários tridimensionais executados e renderizados dos períodos de reconstrução virtual trabalhados neste documento, de acordo com os dados iconográficos coletados, cuja leitura homogênea da modelagem contrasta com os mapas de confiabilidade consecutivos.

1900 a 1910

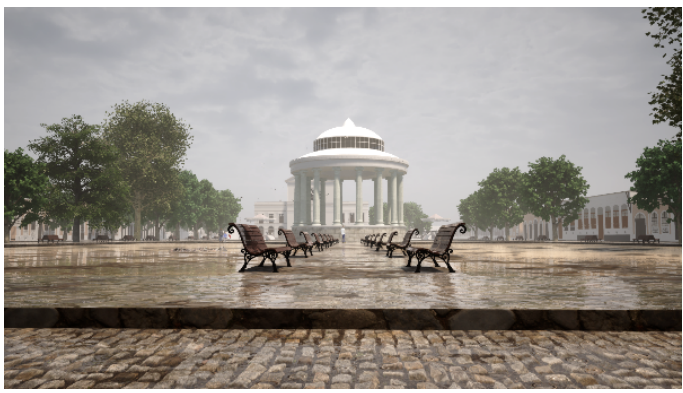

1950 a 1960

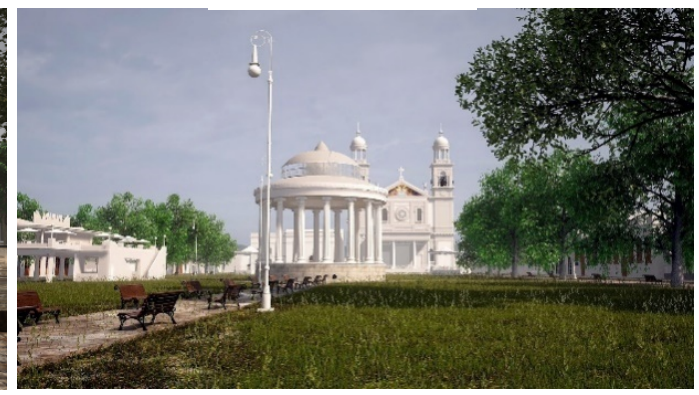

\section{LIMITAÇÕES}

Apesar dos resultados se mostrarem consistentes em relação à fidelidade ao que existia no passado, a ferramenta proposta ainda possui limitações, uma delas é consequência da escolha pela representação bidimensional, isso é positivo do ponto de vista da simplificação, mas há situações que necessitam de uma análise tridimensional, por exemplo, quando um prédio $(\mathrm{A})$ 
situa-se dentro da área de sombreamento de uma outra edificação (B), significando que "A" não é contabilizado, conforme Figura 04. Porém, se o prédio "A" possuir altura suficiente para ser visualizado acima de "B", então uma porção superior da fachada do primeiro deveria receber pontuação, pois ela é visível e certamente ajuda o pesquisador na coleta de informações.

Outra limitação diz respeito à angulação das câmeras em relação à fachada da edificação. Isso porque, se a câmera estiver de frente para um prédio, formando um ângulo próximo a 45 graus, a percepção da configuração espacial provavelmente será boa, entretanto quando tal ângulo inclina drasticamente, aproximando-se, por exemplo, de 180 graus, certamente a qualidade da leitura será reduzida. Este fator ainda não está sendo quantificado, merecendo, portanto, melhorias nas etapas futuras de pesquisa.

Outra limitação é o uso da Geometria de Coleta no formato triangular, isso porque, apesar de ser possível trabalhar com triângulos quase imperceptíveis, ainda pode haver casos em que uma câmera toque um triângulo sem necessariamente visualizar o prédio. De forma similar ao parágrafo anterior, esta limitação pode ser melhorada se houver a inclusão de uma variável que analise o ângulo de inclinação, descartando casos com ângulos demasiadamente inclinados.

A inserção manual de dados obtidos pelas câmeras também representa algo que necessita de melhoria no fluxo proposto, isso pode ser aprimorado com o uso de softwares destinados a coletar dados geométricos de levantamentos fotográficos, informando, por exemplo, sobre a resolução, a distância focal, abertura da lente e outros dados, melhorando consideravelmente a precisão das informações levantadas e representadas (REZENDE, 2018)

\section{CONSIDERAÇÕES}

O tema em discussão segue em consonância com as ideias propostas por Denard (2009a) sobre transparência em reconstruções virtuais de patrimônios históricos (BEACHAM; DENARD; NICCOLUCCI, 2006), e ganha maior relevância quando se acrescenta a importância de comunicar o conteúdo científico a um público não especializado (GIOVANNINI, 2020). Neste sentido, a inquietação por trás da produção de um mapa de calor para expor a confiabilidade das deduções partiu da necessidade de usar uma linguagem simples como meio de informar o usuário sobre quais partes merecem mais credibilidade quanto às evidências do passado.

O fluxo proposto permitiu organizar a coleta de dados iconográficos, aprimorar a cartografia da época e produzir um mapa sobre o grau de confiabilidade. No estudo de caso em questão, a investigação se destinou principalmente à carta geográfica e à casca externa das edificações, porém o princípio do fluxo em pauta pode ser aplicado em outras situações, como na reconstrução 3D do interior de uma edificação ou ainda de um objeto específico.

Observou-se, ainda, que o mapa em questão terminou por mostrar quais prédios e ângulos do passado eram mais fotografados, isso pode ser também interpretado como os trechos urbanos que mais se destacavam visualmente na época, pelos olhares dos fotógrafos, portanto, quando o mapa mostrar uma área avermelhada, pode ser um indicador que tal espaço fazia parte marcante das relações culturais de uma dada época. Evidente que tal afirmação merece um aprofundamento maior, e isso pode ser um tema para pesquisas futuras.

Neste mesmo sentido, vale observar que parte das edificações com maior pontuação, como os coretos e o Clipper, que possivelmente representavam algo relevante na cultura da época, foram demolidos e não houve nada no local que os substituísse, deixando o vazio espacial e a perda da função cultural que tais prédios exerciam naquele espaço urbano. 
Outra contribuição foi o catálogo de fotografias, que condensa diversas informações sobre o lugar, não apenas arquitetônicas e urbanísticas, mas sobre os costumes, vestimenta e outros. Tal catálogo é uma ferramenta preparada para ser ampliada com o passar do tempo, recebendo novas imagens conforme forem descobertas.

A reconstrução digital dos dois períodos do passado permitiu, ainda, produzir materiais como o skyline das quadras e diversas imagens virtuais realísticas, que podem favorecer análises futuras sobre mudanças urbanísticas e arquitetônicas sofridas durante os anos. Tal percepção pode ajudar a estabelecer julgamentos acerca das soluções adotadas no passado e suas consequências para o presente e o futuro (GOMES et al., 2018).

A elaboração de dois mapas de confiabilidade em épocas diferentes referentes ao mesmo lugar exibiu, com clareza, as edificações com maior confiança, deixando claro que cada intervalo de tempo da pesquisa necessita de local em uma nova análise sobre a confiabilidade da reconstrução. Isso permite observar que, mesmo dentro de suas limitações, o algoritmo se mostrou eficiente para representar a "qualidade fotográfica" dos prédios em cada um dos momentos e, por corolário, indicou onde o pesquisador obteve mais confirmações sobre como eram as edificações do lugar. 0 método em pauta pode ainda ser utilizado em um momento preliminar ao proposto aqui, servindo como base comparativa para saber qual época ou local possui mais dados confiáveis para ser ou não reconstituído virtualmente, ou seja, para informar o potencial que determinado conjunto de evidências fotográficas possui.

\section{Referências Bibliográficas}

BASSALO, J. M. C. O Reservatório Paes de Carvalho. F A U - Laboratório Virtual - I T E C / U F P A. 2019 a. Disponível em: <https://fauufpa.org/2019/12/31/o-reservatorio-paes-de-carvalho-por-jose-maria-coelhobassalo/>. Acesso em: 13/abr./20.

O Super Clipper Brasil. F A U - Laboratório Virtual - I T E C / U F P A. 2019b. Disponível em: <https://fauufpa.org/2019/08/24/o-super-clipper-brasil-por-jose-maria-coelho-bassalo/>. Acesso em: 13/abr./20.

BEACHAM, R.; DENARD, H.; NICCOLUCCI, F. An Introduction to the London Charter. The Evolution of ICTechnology in Cultural Heritage, CIPA/VAST/EG/EuroMed, [s.I.], no June 2015, p. 263-9, 2006. ISBN: 9780754675839.

BOAS, N. V. Simuladores Urbanos Digitais : Representação e Interação com a História das Cidades. In: XIX Congresso da Sociedade Ibero-americana de Gráfica Digital 2015. [s.I.]: [s.n.], 2015. Disponível em: <https://www.proceedings.blucher.com.br/article-details/simuladores-urbanos-digitais-representao-einterao-com-a-histria-das-cidades-22333>. DOI: 10.5151/despro-sigradi2015-80027.

CANUTO, C. L.; MOURA, L. R. De; SALGADO, M. S. Tecnologias digitais e preservação do patrimônio arquitetônico: explorando alternativas. PARC Pesquisa em Arquitetura e Construção, [s.I.], v. 7, no 4, p. 252, 2016. DOI: 10.20396/parc.v7i4.8647456.

D'AGOSTINO, Mário Henrique Simão; CALDEIRAS, Lucas Frech; BORBA, Ibrahim Massaru de. Largo São Francisco: modelagens de uma memória. Minha Cidade, São Paulo, ano 20, n. 239.07, Vitruvius, jun. 2020 <https://vitruvius.com.br/revistas/read/minhacidade/20.239/7785>.

DEBEVEC, P.; YU, Y.; BORSHUKOV, G. Efficient View-Dependent Image-Based Rendering with Projective TextureMapping. [s.I.], p. 105-116, 1998. DOI: 10.1007/978-3-7091-6453-2_10.

DENARD, H. Carta de londres para a visualização computarizada do património cultural. [s.l.], p. 1-15, 2009.

ELISEO, M. A. et al. Visualização imersiva do patrimônio histórico : Um modelo espaço-temporal para o campus Immersed visualization of the historical patrimony. A time and space model for the. SIGraDi 2009 sp, [s.I.], 2009. 
GIOVANNINI, E. C. WORKFLOW for AN EVIDENCE-BASED VIRTUAL RECONSTRUCTION: The MARBLES of the CIBORIUM of the EARLY MEDIEVAL MONTE SORBO CHURCH. International Archives of the Photogrammetry, Remote Sensing and Spatial Information Sciences - ISPRS Archives, [s.I.], v. 43, n B2, p. 1395-1402, 2020. ISSN: 16821750, DOI: 10.5194/isprs-archives-XLIII-B2-2020-1395-2020.

GOMES, E. B. de O. et al. The Virtual Reality as a tool to analyze modifications in the architecture of the city. Case study: the historical center of the city of Belém-Pará. [s.I.], p. 860-865, 2018. DOI: 10.5151/sigradi20181412 .

IPHAN. (2006). DOSSIÊ IPHAN I - Círio de Nazaré.

KOZAN, J. M.; KOZAN, I. B. Reconstrução virtual da antiga Igreja Matriz de Curitiba : Análise de dimensões e implantação. Arqueologia, Cincinnati, v. 10, no 1, p. 1, 2007.

MARQUES, M.; COSTA, T. Representação do Sítio Arqueológico da Pedra de Ingá com Realidade Virtual. Anais do Workshop de ..., [s.I.], no Figura 1, p. 1-4, 2009.

MCMILLAN, L.; BISHOP, G. Plenoptic modeling: an image-based rendering system. In: Proceedings of the ACM SIGGRAPH Conference on Computer Graphics. [s.I.]: [s.n.], 1995. ISBN: 0897917014.

MELO, Tainara L. A REALIDADE VIRTUAL COMOESTUDO DO PATRIMÔNIO HISTÓRICO: a reconstrução da Fábrica Palmeira e seu entorno em Belém/PA. Trabalho de Conclusão de Curso (Graduação)- Universidade da Amazônia (UNAMA), Belém, Pará, 2020.

PARAIZO, R. C. 101 Conceitos de Arquitetura e Urbanismo na Era Digital. 101 Conceitos de Arquitetura E Urbanismo na Era Digital. [s.I.]: ProBooks, 2016. p. 128-129; 145-146; 160-161; 178-179.

RAIOL, Karen. K. O. ARQUITETURA, HISTÓRIA ETECNOLOGIA: O GRANDE HOTEL DE BELÉM EM REALIDADE VIRTUAL. Trabalho de Conclusão de Curso (Graduação)- Universidade da Amazônia (UNAMA), Belém,Pará, 2017..

REILLY, P. (IBM U. Towards a Virtual Archaeology. CAA90. Computer Applications and Quantitative Methods in Archaeology 1990, [s.I.], p. 132-139, 1991.

REZENDE, W. de S. Do analógico ao digital: a evolução das técnicas de documentação do ambiente construído. In: EDITORIAL, P. (Org.). Jundiaí: [s.n.], 2018. ISBN: 9788546206308.

SARGES, M. de N. Belém: riquezas produzindo a Belle Époque (1870-1912). 3a edição ed. Belém: Paka- Tatu, 2010.

VIDAL, C. N. C. P. Experiências Do Moderno Em Belém : Construção, Recepção. V!RUS, São Carlos, [s.I.], v. n. 12, 2016.

ZUFFO, M. K.; LOPES, R. de D. Ambientes de realidade virtual e realidade aumentada na preservaçao do patrimônio histórico. Proceedings of Seminário Computação gráfica: pesquisas e projetos rumo à Educação Patrimonial. São Paulo, AHMWL/DPH/SMC/PMSP, [s.I.], p. 1-6, 2008.

\section{Emerson Bruno de Oliveira Gomes}

b.emersongomes@gmail.com

Talita Simão Luiz Araujo talitaaraujo_s@hotmail.com

Abner Simões Portilho Ferraz portilh011@gmail.com

Anna-Beatriz Bassalo Aflalo annabeatrizaflalo@gmail.com 